\title{
Pendekatan Kontekstual dalam Meningkatkan Penguasaan Konsep Bangun Ruang
}

\author{
Mawarni \\ SDN 139/V PKMT Taman Raja, Jl. Lintas Timur Sumatera, Kabupaten Tanjung Jabung \\ Barat, Indonesia \\ email: mawarni.edu@gmail.com
}

\begin{abstract}
This study aims to improve student mathematics learning outcomes on the topic of solid figure through the implementation of contextual approach. This research is a classroom action research (CAR) conducted in class VI B SDN 139 / V PKMT Taman Raja. Subjects in this study were 29 students. Students have difficulty in the process of abstraction of mathematical concepts and tend to be less motivated to learn. In applying the contextual approach, students are given problems that are often encountered in everyday life and collaborative learning. The results showed that students experienced an increase in mastery of concepts as indicated by an increase in the average score of 21.61 in the pre cycle, 57.47 in the first cycle, and 79.77 in the second cycle.
\end{abstract}

Keywords: Contextual approach; conceptual understanding; solid figure.

\begin{abstract}
Abstrak
Penelitian ini bertujuan untuk memperbaiki hasil belajar matematika siswa pada topik bangun ruang melalui implementasi pendekatan kontekstual. Penelitian ini merupakan penelitian tindakan kelas (PTK) yang dilaksanakan di kelas VI B SDN 139/V PKMT Taman Raja. Subjek dalam penelitian ini adalah 29 siswa. Siswa mengalami kesulitan dalam proses abstraksi konsep matematika dan cenderung kurang termotivasi untuk belajar. Dalam penerapan pendekatan kontekstual, siswa diberikan permasalahan yang sering ditemui dalam kehidupan sehari-hari dan belajar secara kolaboratif. Hasil menunjukkan bahwa siswa mengalami peningkatan penguasaan konsep yang diindikasi dari peningkatan rata-rata skor yakni 21,61 pada pra siklus, 57,47 pada siklus 1 , dan 79,77 pada siklus 2 .
\end{abstract}

Kata Kunci: Pendekatan kontekstual; penguasaan konsep; bangun ruang.

\section{PENDAHULUAN}

Pendidikan berperan penting dalam mengembangkan kualitas dan mutu sumber daya manusia. Dengan sumber daya yang baik maka kemajuan sebuah negara akan lebih mudah dicapai (Rahmadani, 2019). Kunci ketercapaian tujuan pendidikan adalah pada proses pembelajaran yang baik.

$$
\text { Pembelajaran }
$$

yang dilaksanakan pada hakikatnya bertujuan untuk memberikan pengalaman kepada siswa. Pembelajaran bermuara pada perubahan tingkah laku siswa menjadi lebih baik (Kasri, 2018; Pujiati, 2017; 
Taqwa, Astalini, \& Darmaji, 2015), begitu pula pada kompetensi siswa yang lebih matang. Pembelajaran matematika sangat diperlukan oleh siswa dalam menjelaskan bermacam fenomena alam karena matematika adalah pemodelan yang paling baik untuk dapat diterima secara rasional. Oleh karena itu, pembelajaran hendaknya mampu memfasilitasi siswa untuk memahami konsep dengan mendalam hingga konsep-konsep tersebut berguna untuk memecahkan bermacam fenomena (Docktor \& Mestre, 2014; Hegde \& Meera, 2012; Maloney, 1994; Ryan, Frodermann, Heller, Hsu, \& Mason, 2016; Sajadi, Amiripour, \& Rostamy-Malkhalifeh, 2013; Soong, Mercer, \& Er, 2009; Taqwa, 2017, 2018).

Matematika merupakan pelajaran yang menjawab akan beberapa tantangan yang ada saat ini dan masa depan. Hampir seluruh aspek kehidupan berkaitan dengan matematika. Matematika digunakan dalam banyak disiplin ilmu (Pujayastri, 2018). Penting bagi siswa mempelajari matematika dengan baik (Saputra, 2017) untuk mendukung ketercapaian pelajaran-pelajaran lain. Oleh karena itu, pendidikan matematika seharusnya bertindak sebagai proses yang aktif, generatif, dan dinamik melalui doing math. Hal tersebut memberikan sumbangan yang penting kepada siswa dalam mengembangkan kemampuan mereka, seperti perpikir logis, matematis, kritis, dan cermat.

Kontras dengan kondisi di kelas, siswa justru mengalami bermacam kendala dalam memahami konsep matematika. Kendala tersebut disebabkan oleh beberapa hal, seperti siswa yang telah membawa pemahaman keliru ketika masuk kedalam kelas (Docktor, Strand, Mestre, \& Ross, 2010), kemampuan abstraksi siswa yang terbatas, minat siswa yang rendah, dan sebab-sebab lainnya. Permasalahan tersebut terjadi di kelas VI B SDN 139/V PKMT Taman Raja. Dalam belajar matematika, siswa sering kali merasa kesulitan dan tidak memiliki motivasi belajar dengan baik. Kesulitan dan rendahnya motivasi menyebabkan hasil belajar mengenai apa yang seharusnya digali oleh peserta (Nuryasana, 2019) didik menjadi rendah. Padahal, motivasi belajar merupakan hal penting yang mendorong peserta didik untuk mencapai prestasi (Prinotama, Larasati, \& Roosyanti, 2019) dan hasil belajar yang baik.

Permasalahan tersebut merupakan permasalahan umum yang dialami dalam proses pembelajaran matematika. Untuk memecahkan permasalahan tersebut diperlukan adanya pendekatan pembelajaran yang dapat memotivasi siswa untuk belajar sehingga penguasaan konsep matematikanya akan memadai. Salah satu pendekatan yang dapat digunakan adalah pendekatan kontekstual, yang merupakan salah satu pembelajaran inovatif dalam pengajaran matematika.

$$
\text { Pendekatan pembelajaran }
$$
kontekstual lebih mengutamakan aktifitas siswa dalam pembelajaran sehingga siswa dapat menemukan konsep tentang materi pembelajaran dan mengaitkan konsep tersebut dengan 
situasi dunia nyata. Pendekatan kontekstual ini merupakan salah satu pendekatan yang dapat digunakan untuk meciptakan pembelajaran dengan kondisi kelas yang kondusif dan lebih memberdayakan siswa (Sariningsih, 2014).

Pembelajaran

dengan

pendekatan kontekstual dimulai dengan mengambil (dapat mensimulasikan, menceritakan, atau bahkan mengajak mengamati langsung) kejadian nyata yang ada dalam kehidupan sehari-hari yang kemudian diangkat dalam konsep matematika yang akan dipelajari oleh siswa (Suherman, 2006). Dalam pembelajaran kontektual terdapat beberapa aktivitas yang harus dikembangkan, diantaranya (1) belajar berbasis masalah; (2) belajar dengan multi konteks; (3) belajar mandiri; (4) penilaian otentik; dan (5) masyarakat belajar (Berns \& Erickson, 2001).

Dengan

implementasi

pendekatan kontekstual dalam

pembelajaran dapat meningkatkan

minat siswa dari berbagai latar

belakang serta mampu meningkatkan

peran aktif sisiwa dalam mengonstruk pengetahuan mereka hingga menggunakan pengetahuannya untuk menyelesaikan berbagai permasalahan dalam kehidupan sehari-hari (Owens, 2001). Hal ini juga sejalan dengan penelitian Mulhamah, Susilahudin Putrawangsa (2016) penerapan pendekatan pembelajaran kontekstual seperti yang dilakukan pada penelitian ini dapat meningkatkan kemampuan pemecahan masalah siswa pada mata pelajaran matematika.
Pendekatan

kontekstual

merupakan pendekatan pembelajaran yang dibangun berdasarkan teori belajar konstruktivisme. Konstruktivisme percaya bahwa siswa mampu membangun pengetahuannya (ranah kognitif) dalam kegiatan pembelajaran. Mengimplementasikan pendekatan konstruktivistik dalam pembelajaran melalui pengamatan hasil penelitian dapat mengatasi kejenuhan siswa dalam belajar, dengan memperlihatkan siswa pada objek langsung, mengingatkan kembali pengalaman yang dilalui, dan menjadikan siswa sebagai pusat pembelajaran dapat memusatkan perhatian siswa pada materi pembelajaran. (Subaedah, 2016)

$$
\text { Dengan memperhatikan }
$$

karakteristik pendekatan kontekstual tersebut maka diharapkan implementasi pendekatan kontekstual dapat meningkatkan capaian hasil pembelajaran berupa penguasaan konsep matematis siswa. Dalam artikel ini akan membahas impelentasi pendekatan kontekstual terhadap penguasaan matematika siswa pada topik bangun ruang.

\section{METODE PENELITIAN}

Desain penelitian yang digunakan dalam penelitian ini adalah Penelitian Tindakan Kelas (PTK). PTK berguna untuk mengatasi permasalahan yang terjadi di lingkup kelas seuai dengan karakteristik permasalahan yang muncul (Afandi, 2014). Model penelitian tindakan kelas yang digunakan adalah yang dikembangkan oleh Kemmis, McTaggart, \& Nixon 
(2013). Model yang dikembangkan implementasi seperti yang ditunjukkan tersebut dilaksanakan dengan tahapan Gambar 1.

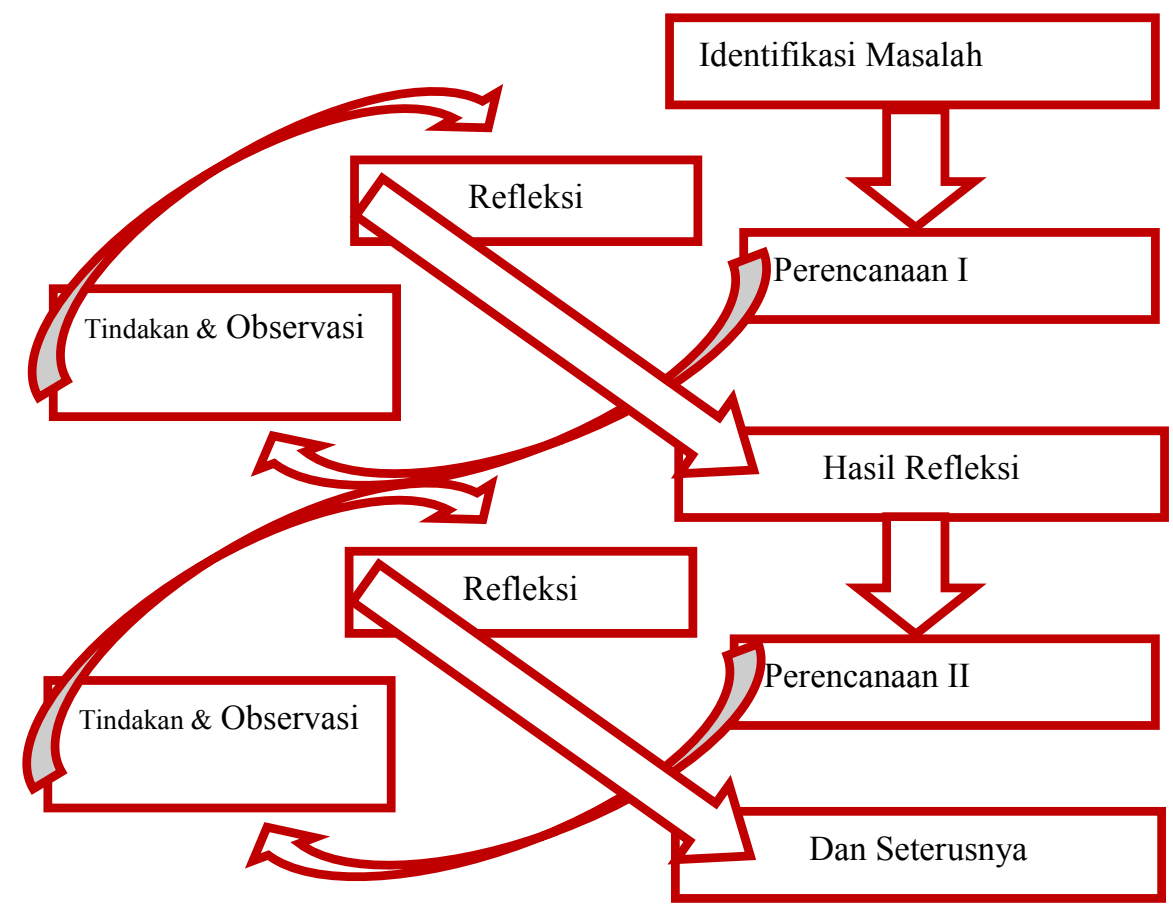

Gambar 1. Penelitian Tindakan Kelas dengan Model Kemmis \& McTaggar

Dalam menggunakan model di SDN 139/V PKMT Taman Raja, yang dikembangkan oleh Kemmis, Provinsi Jambi. Penelitian ini dilakukan McTaggart, \& Nixon, penelitian pada siswa kelas VI B dengan jumlah tindakan kelas ini menerapkan empat siswa sebanyak 29 siswa dengan 15 tahapan, yakni tahapan perencanaan, siswa laki-laki dan 14 siswa tahapan tindakan, tahapan pengamatan, perempuan.

dan tahapan refleksi. Dalam Penelitian ini bertujuan untuk implementasi model tersebut, tahapan memperbaiki proses pembelajaran tindakan dan pengamatan dilakukan berdasarkan permasalahan yang ada di secara serentak. Hal tersebut dilakukan kelas. Dalam hal ini, perbaikan tersebut dengan pertimbangan karena keduanya difokuskan pada peningkatan saling terkait satu sama lain dan penguasaan konsep matematika siswa pengamatan seharusnya dilaksanakan pada topik bangun ruang. Hasil belajar selama proses pemberian tindakan siswa diperoleh dengan memberikan (Kastiniwati, 2019). Implementasi soal tes berupa 15 soal pilihan berganda pendekatan kontekstual dalam yang telah layak berdasarkan expert penelitian tindakan kelas ini dilakukan judgement dan uji empirik. 


\section{HASIL DAN PEMBAHASAN}

\section{Pelaksanaan Tindakan}

Pembelajaran yang dilakukan dalam penelitian ini adalah dengan menerapkan pendekatan kontekstual. Pada siklus pertama, pelaksanaan pembelajaran berlangsung lancar. Pelaksanaan pembelajaran dengan pendekatan kontekstual dilaksanakan dengan mengenali bangun-bangun ruang melalui benda-benda yang ada dalam kehidupan sekitar. Pengenalan bangun ruang dimulai dengan memunculkan permasalahan sederhana bagi siswa, sesuai dengan karakteristik pendekatan kontekstual (Rahmawati, 2013). Hal tersebut bertujuan agar dapat mengidentifikasi sifat-sifat bangun ruang. Selain itu, siswa dituntut untuk mengamati lingkungan untuk menemukan benda-benda dengan bentuk ruang tertentu dan diminta untuk mengidentifikasi sifat-sifatnya secara mandiri. Kemandirian ini penting agar siswa mampu mengonstruk pengetahuan mereka dengan baik sesuai bidikan pendekatan kontekstual (Sariningsih, 2014).

Pada siklus pertama, siswa sedikit mengalami kesulitan ketika memecahkan persoalan matematis. Hal ini disesbabkan karena proses pembelajaran cenderung membutuhkan waktu yang relatif lebih lama jika dibandingkan dengan pembelajaran konvensional. Namun demikian, pendekatan kontekstual ini perlu tetap diimplementasikan agar siswa dapat memahami konsep secara lebih mendalam. Selain itu, pembelajaran dengan pendekatan kontekstual ini lebih baik dibandingkan dengan pembelajaran konvensional dalam mengembangkan beberapa aspek kemampuan matematis menurut beberapa penelitian (Bernard, 2015; Rosmaiyadi, Mariyam, \& Juliyanti, 2018). Pada siklus kedua proses pembelajaran lebih baik dibandingkan dengan siklus pertama. Pembelajaran dilaksanakan dengan lebih terkondisi dengan penggunaan waktu diusahakan lebih efisien sehingga siswa tetap diberi drill latihan-latihan soal yang memadai.

\section{Penguasaan Konsep Bangun Ruang}

Dalam artikel ini, hasil yang diperoleh berupa skor penguasaan konsep siswa pada topik bangun ruang. Rata-rata skor siswa dari kegiatan pra siklus, siklus 1, dan siklus 2 seperti yang ditunjukkan pada Gambar 2.

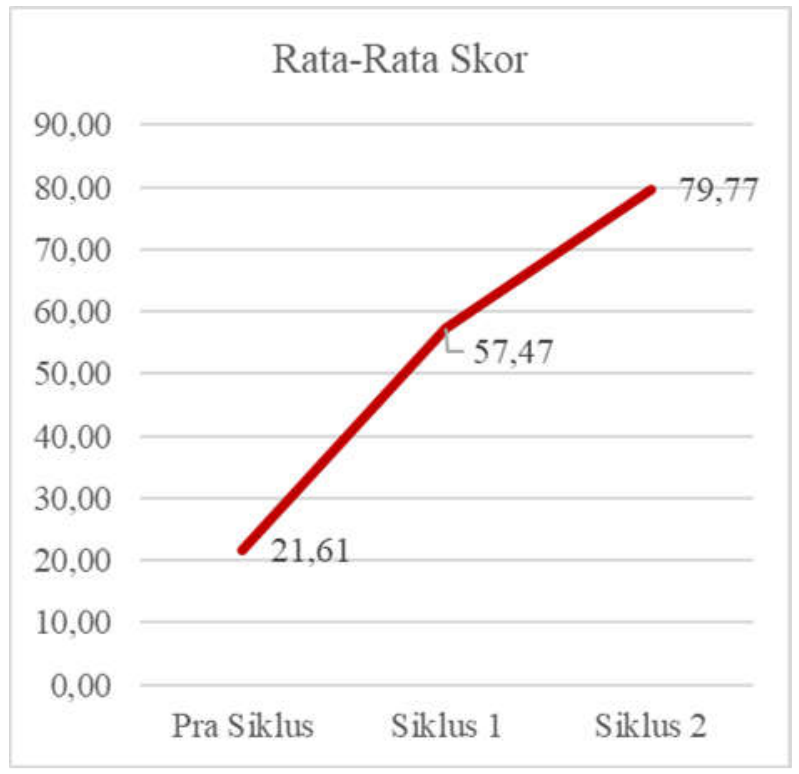

Gambar 2. Rata-Rata Skor Penguasaan Konsep Bangun Ruang

Implementasi pendekatan kontekstual dalam pembelajaran matematika topik bangun ruang 
berdampak positif terhadap peningkatan penguasaan konsep siswa. Hal tersebut diindikasi dari meningkatnya nilai rata-rata siswa dari pra siklus, siklus 1, dan siklus 2. Pada pra siklus rata-rata skor siswa hanya 21,61 dan meningkat sebesar 35,86 pada siklus 1 menjadi 57,47. Dari siklus 1 ke siklus 2 rata-rata skor siswa juga mengalami peningkatan, yakni menjadi sebesar 79,77. Lebih lanjut, hasil skor masing-masing siswa untuk tiap siklus adalah seperti yang ditunjukkan Tabel 1.

Tabel 1. Skor Masing-Masing Siswa pada Tiap Siklus

\begin{tabular}{|c|c|c|c|}
\hline No & $\begin{array}{c}\text { Pra } \\
\text { Siklus }\end{array}$ & Siklus 1 & Siklus 2 \\
\hline 1 & 20,00 & 40,00 & 73,33 \\
\hline 2 & 26,67 & 46,67 & 80,00 \\
\hline 3 & 33,33 & 46,67 & 80,00 \\
\hline 4 & 13,33 & 46,67 & 86,67 \\
\hline 5 & 6,67 & 40,00 & 86,67 \\
\hline 6 & 13,33 & 53,33 & 86,67 \\
\hline 7 & 26,67 & 40,00 & 93,33 \\
\hline 8 & 20,00 & 53,33 & 93,33 \\
\hline 9 & 20,00 & 60,00 & 86,67 \\
\hline 10 & 0,00 & 40,00 & 86,67 \\
\hline 11 & 13,33 & 80,00 & 86,67 \\
\hline 12 & 13,33 & 66,67 & 100,00 \\
\hline 13 & 13,33 & 66,67 & 86,67 \\
\hline 14 & 20,00 & 80,00 & 86,67 \\
\hline 15 & 26,67 & 73,33 & 93,33 \\
\hline 16 & 33,33 & 60,00 & 93,33 \\
\hline 17 & 33,33 & 60,00 & 86,67 \\
\hline 18 & 40,00 & 53,33 & 60,00 \\
\hline 19 & 20,00 & 53,33 & 60,00 \\
\hline 20 & 13,33 & 60,00 & 86,67 \\
\hline 21 & 26,67 & 80,00 & 80,00 \\
\hline 22 & 26,67 & 60,00 & 73,33 \\
\hline 23 & 13,33 & 60,00 & 60,00 \\
\hline
\end{tabular}

\begin{tabular}{|c|c|c|c|}
\hline No & $\begin{array}{c}\text { Pra } \\
\text { Siklus } \\
\end{array}$ & Siklus 1 & Siklus 2 \\
\hline 24 & 33,33 & 60,00 & 46,67 \\
\hline 25 & 40,00 & 66,67 & 80,00 \\
\hline 26 & 26,67 & 53,33 & 73,33 \\
\hline 27 & 20,00 & 60,00 & 73,33 \\
\hline 28 & 13,33 & 60,00 & 73,33 \\
\hline 29 & 20,00 & 46,67 & 60,00 \\
\hline
\end{tabular}

Berdasarkan data yang diperoleh dari hasil penelitian menunjukkan bahwa terdapat dampak positif implementasi pendekatan kontekstual dalam pembelajaran matematika topik bangun ruang. Hal tersebut diindikasi dari peningkatan skor pemahaman konsep siswa dari pra siklus ke siklus 1 dan dari siklus 1 ke siklus 2. Penerapan pendekatan kontekstual ini sejalan dengan hakikat belajar matematika, yakni pembelajaran yang memnggiring siswa mengalami proses berpikir yang disertai dengan aktivitas afektif dan fisik (Suherman, 2006). Dengan keterlibatan siswa dalam proses belajar, maka siswa akan cenderung lebih tertarik dan tidak mudah bosan.

Tidak hanya dalam pembelajaran matematika, seperti hasil temuan Faqih (2019) yang mengklaim bahwa rendahnya hasil belajar siswa disebabkan oleh pembelajaran yang masih terfokus pada guru, bukan siswa. Berbeda dengan pendekatan kontekstual, siswa diajak untuk aktif dalam membangun pengetahuan sehingga tidak pasif hanya menerima apa yang disampaikan guru.

Dalam implementasi pendekatan kontekstual siswa dihadapkan dengan permasalahan yang 
sering mereka temui di kehidupan sehari-hari, bukan hanya sekedar kasus yang abstrak. Dengan permasalahan kontekstual yang ada, siswa akan lebih baik dalam menggunakan ide yang mereka miliki untuk memecahkan permasalahan (Tambelu, 2013) sehingga penguasaan konsep mereka menjadi lebih mendalam. Lebih jauh, siswa yang terbiasa dalam mengahadapi permasalahan kontekstual maka akan terlatih dalam melibatkan metakognisinya dan melakukan evaluasi akan ketercapaian tujuan pemecahan masalah (Anggo, 2011).

Pelaksanaan pembelajaran juga

tidak dilaksanakan secara individual oleh siswa namun kolaborasi. Selain mempermudah belajar siswa, dengan kolaborasi siswa juga terlatih untuk saling bekerja sama. Dengan pembelajaran kooperatif, hasil belajar matematika siswa akan meningkat dengan peningkatan lebih baik dari pada siswa dengan belajar secara individual. Selain itu, siswa terlihat lebih antusias dan termotivasi ketika belajar secara berkelompok. Kemampuan untuk berdiskusi ini penting pula untuk melatih kemampuan komunikasi siswa sejak dini sesuai dengan tuntutan abad 21.

\section{SIMPULAN}

Permasalahan yang terjadi di kelas VI B SDN 139/V PKMT Taman Raja yakni kemampuan abstraksi siswa terbatas, dan minat belajar yang masih rendah sehingga membawa dampak pada rendahnya hasil belajar siswa. Permasalahan tersebut berusaha direduksi dengan menerapkan pendekatan kontekstual. Hasil penelitian menunjukkan adanya peningkatan rata-rata skor penguasaan konsep bangun ruang yakni sebesar 21,61 saat pra siklus, 57,47 saat siklus 1 dan 79,77 saat siklus 2. Pendekatan kontekstual ini efektif dalam meningkatkan penguasaan konsep siswa karena siswa belajar melalui permasalahan yang sering mereka temui dalam kehidupan sehari-hari. Selain itu, siswa juga belajar secara kolaboratif dan hal tersebut menunjukkan adanya peningkatan motivasi belajar siswa.

\section{DAFTAR RUJUKAN}

Afandi, M. (2014). Pentingnya Penelitian Tindakan Kelas Bagi Guru dalam Pembelajaran di Sekolah Dasar. Jurnal Ilmiah Pendidikan Dasar, 1(1), 1-19.

Anggo, M. (2011). Pemecahan masalah matematika kontekstual untuk meningkatkan kemampuan metakognisi siswa. Edumatica: Jurnal Pendidikan Matematika.

Bernard, M. (2015). Meningkatkan kemampuan komunikasi dan penalaran serta disposisi matematik siswa SMK dengan pendekatan kontekstual melalui game adobe flash cs 4.0. Infinity Journal, 4(2), 197-222.

Berns, R. G., \& Erickson, P. M. (2001). Contextual Teaching and Learning: Preparing Students for 
the New Economy. The Highlight Zone:Research@WorkNo.5.

Docktor, J. L., \& Mestre, J. P. (2014). Synthesis of discipline-based education research in physics. Physical Review Special TopicsPhysics Education Research, 10(2), 020119.

Docktor, J. L., Strand, N. E., Mestre, J. P., \& Ross, B. H. (2010). A conceptual approach to physics problem solving. AIP Conference Proceedings, 1289, 137-140. AIP.

Faqih, N. (2019). Peningkatan Aktivitas dan Hasil Belajar Siswa pada Pembelajaran IPA Materi Gerak Benda Melalui Pendekatan Saintifik. Trapsila: Jurnal Pendidikan Dasar, 1(01), 8-18.

Hegde, B., \& Meera, B. N. (2012). How do they solve it? An insight into the learner's approach to the mechanism of physics problem solving. Physical Review Special Topics-Physics Education Research, 8(1), 010109.

Kasri, K. (2018). Peningkatan Prestasi Belajar Matematika melalui Media Puzzle Siswa Kelas I SD. Jurnal Pendidikan: Riset dan Konseptual, 2(3), 320-325.

Kastiniwati, K. (2019). Peningkatan Aktivitas Hasil Belajar Kognitif Materi Penjumlahan dan Pengurangan Melalui Media
Konkret. Briliant: Jurnal Riset dan Konseptual, 4(3), 274-281.

Kemmis, S., McTaggart, R., \& Nixon, R. (2013). The action research planner: Doing critical participatory action research. Springer Science \& Business Media.

Maloney, D. P. (1994). Research on problem solving: Physics. Handbook of research on science teaching and learning, 327-354.

Mulhamah, Susilahudin Putrawangsa. (2016). Penerapan Pembelajaran Kontekstual dalam Meningkatkan Kemampuan Pemecahan Masalah Matematika. Jurnal Pendidikan Matematika Volume 10 No.1 Januari 2016, 59-80.

Nuryasana, E. (2019). Keefektifan Model Pembelajaran Think Pair Share (TPS) dan Model Pembelajaran Inkuiri terhadap Hasil Belajar IPA Siswa Kelas V Sekolah Dasar. Trapsila: Jurnal Pendidikan Dasar, 1(01), 72-80.

Owens, T. (2001). Teacher Preparation for Contextual Teaching and Learning A Statewide Consortium Model. Portland, Oregon.

Prinotama, A. N., Larasati, D. A., \& Roosyanti, A. (2019). Pengaruh Joyfull Learning terhadap Motivasi Belajar di SDN Karah I Surabaya. Trapsila: Jurnal 
Pendidikan Dasar, 1(01), 96105.

Pujayastri, A. (2018). Model Remated

(Realistic

Mathematic

Education): MeningkatKan Hasil

Belajar Matematika Materi

Pengukuran. Jurnal Pendidikan:

Riset dan Konseptual, 2(2), 189195.

Pujiati, P. (2017). Penerapan Metode

Smart Games dalam Upaya

Peningkatan Hasil Belajar

Operasi Bilangan Bulat pada

Siswa SMP. Jurnal Pendidikan:

Riset dan Konseptual, 1(1), 120125.

Rahmadani, A. (2019). Keefektifan

Model Pembelajaran Kooperatif

Tipe TGT (Team Games

Tournament) pada Pokok

Bahasan Pecahan Sederhana

Kelas III SDN Tanjungsari 1

Sidoarjo. Trapsila: Jurnal

Pendidikan Dasar, 1(01), 55-71.

Rahmawati, F. (2013). Pengaruh

Pendekatan Pendidikan Realistik

Matematika dalam Meningkatkan

Kemampuan Komunikasi

Matematis Siswa Sekolah Dasar.

Prosiding SEMIRATA 2013, 1(1).

Rosmaiyadi, R., Mariyam, M., \& Juliyanti, J. (2018). Pemahaman Konsep Matematis Siswa Dengan Strategi Pembelajaran Group To Gruop Exchange Berpendekatan Kontekstual. JPPM (Jurnal
Penelitian dan Pembelajaran Matematika), 11(1).

Ryan, Q. X., Frodermann, E., Heller, K., Hsu, L., \& Mason, A. (2016). Computer problem-solving coaches for introductory physics: Design and usability studies. Physical Review Physics Education Research, 12(1), 010105.

Sajadi, M., Amiripour, P., \& RostamyMalkhalifeh, M. (2013). The examining mathematical word problems solving ability under efficient representation aspect. Mathematics Education Trends and Research, 2013, 1-11.

Saputra, Y. D. (2017). Penerapan Strategi I-Care berbantuan EModul untuk Meningkatkan Hasil Belajar Materi Bangun Ruang Sisi Lengkung. Jurnal Pendidikan: Riset dan Konseptual, 1(1), 38-44.

Sariningsih, R. (2014). Pendekatan kontekstual untuk meningkatkan kemampuan pemahaman matematis siswa SMP. Infinity Journal, 3(2), 150-163.

Soong, B., Mercer, N., \& Er, S. S. (2009). Students' difficulties when solving physics problems: Results from an ICT-infused revision intervention. Proceedings of the 17th International Conference on 
Computers in Education (ICCE), 361-365.

Subaedah, (2016), Implementasi Pendekatan Konstruktivistik pada Pembelajaran Sains di SMP Negeri 34 Makassar Sulawesi Selatan, Jurnal Administrasi Publik Vol 6 No. 1, 88-95

Suherman, E. (2006). Pendekatan kontekstual dalam pembelajaran matematika. Educare, 2(1).

Tambelu, J. V. (2013). Development of mathematical learning based contextual model in south minahasa regency. Development, $4(15)$.

Taqwa, M. R. A. (2017). Profil pemahaman konsep mahasiswa dalam menentukan arah resultan gaya. Prosiding Seminar Nasional Pendidikan Sains, 7987. Surabaya: Universitas Negeri Surabaya.

Taqwa, M. R. A. (2018). Kekeliruan Memahami Konsep Gaya, Apakah Pasti Miskonsepsi? Jurnal Inovasi Pendidikan Fisika Dan Integrasinya, 1(02), 1-12.

Taqwa, M. R. A., Astalini, \& Darmaji. (2015). Hubungan Gaya Belajar Visual, Auditorial, dan Kinestetik dengan Hasil Belajar Siswa Pada Materi Dinamika Rotasi dan Kesetimbangan Benda Tegar Kelas XI IPA SMA Se-Kota Jambi. 220-227. Purworejo: Universitas Purworejo. 